\title{
Herramientas digitales de comunicación en contexto COVID 19. El impacto en la relación estudiantes-instituciones educativas en Argentina
}

\section{Digital communication tools in COVID 19 context. The impact on the relationship between students and educational institutions in Argentina \\ Ferramentas de comunicação digital no contexto COVID 19. $O$ impacto na relação entre estudantes e instituições educacionais na Argentina}

\author{
Claudia Ardini ${ }^{1}$ \\ Universidad Nacional de Córdoba (Argentina) \\ claudiaardini@gmail.com \\ María Belén Barroso ${ }^{2}$ \\ Universidad de Málaga (España) \\ mbelenbarroso@uma.es \\ Leonardo Corzo ${ }^{3}$ \\ Universidad Nacional de Córdoba (Argentina) \\ leonardocorz091@gmail.com
}

Fecha de recepción: 10 de agosto de 2020

Fecha de recepción evaluador: 15 de agosto de 2020

Fecha de recepción corrección: 18 de agosto de 2020

\footnotetext{
${ }^{1}$ Doctora en Semiótica por el Centro de Estudios Avanzados de la UNC. Licenciada en Comunicación Social UNC. Posdoctorado en Ciencias Sociales de la FFyL- UBA. Integrante de la Cátedra Latinoamericana de Narrativas Transmedia. ORCID: https://orcid.org/0000-0001-8106-4070

${ }^{2}$ Doctoranda en Comunicación y Máster en Educación Ambiental por la Universidad de Málaga (España). Investigadora en Comunicación Transmedia social y educativa de la Universidad Nacional de Córdoba (Argentina). Asesora en comunicación del triple impacto. ORCID: https://orcid.org/0000-0001-8411-0458

${ }^{3}$ Licenciado en Comunicación Social con orientación en Comunicación Institucional. Investigador en comunicación digital y narrativas transmedia. ORCID: https://orcid.org/0000-0002-6922-5780
} 


\title{
Resumen
}

Las condiciones en las que los y las estudiantes están atravesando sus procesos de aprendizaje en el contexto de excepcionalidad debido al Aislamiento Social Preventivo (ASPO) y Obligatorio (Decreto Presidencial N²97/2020) ante la pandemia COVID-19 son atípicas y complejas. Por ello, la presente investigación procura analizar las experiencias de aprendizaje virtual que permitirán planificar la comunicación educativa en los procesos de enseñanza-aprendizaje; y a su vez, identificar perspectivas y expectativas a futuro sobre un sistema educativo turbulento e hipermediático. Para el logro de los objetivos, se aplicó un cuestionario aleatorio a 194 estudiantes de los niveles educativos primario, secundario y superior/universitario de la Provincia de Córdoba (Argentina). A partir de los datos recopilados se evidencian oportunidades de mejora, así como obstáculos a superar; además la continuidad de problemáticas preexistentes se profundiza a partir de la pandemia y surgen nuevos cuestionamientos sobre cómo generar una educación comprometida con el pleno desarrollo de las personas y sociedades. Una educación con conciencia de las transformaciones del entorno y la evolución tecnológica, pero a la vez con eje en las personas, sus libertades y potencialidades. Escuchar lo que tienen para decir las y los jóvenes protagonistas del sistema educativo es un primer paso hacia la conquista de una educación que, sin olvidar el pasado, habite su tiempo y avance en la construcción de la sociedad que cada persona merece.

Palabras clave: Educación, Tecnología, Comunicación, COVID 19

\begin{abstract}
The conditions in which students are going through their learning processes in the context of exceptionality due to Preventive Social Isolation (ASPO) and Mandatory (Presidential Decree No. 297/2020) in the face of the COVID-19 pandemic are atypical and complex. Therefore, this research attempts to analyze virtual learning experiences that will allow planning educational communication in the teaching-learning processes; and at the same time, to identify future perspectives and expectations about a turbulent and hypermedia educational system. To achieve the objectives, a random questionnaire was applied to 194 students of the primary, secondary and higher / university educational levels of the Province of Córdoba (Argentina). From the data collected, opportunities for improvement are evident as well as obstacles to overcome; Furthermore, the continuity of pre-existing problems deepens from the pandemic and new questions arise about how to generate an education committed to the full development of people and societies. An education with awareness of the transformations of the environment and technological evolution, but at the same time focused on people, their freedoms and potentialities. Listening to what the young protagonists of the educational system have to say is a first step towards the achievement of an education that, without forgetting the past, inhabits its time and advances in the construction of the society that each person deserves.
\end{abstract}

Keywords: Education, Technology, Communication, COVID 19 


\section{Resumo}

As condições em que os alunos estão a vivenciar os seus processos de aprendizagem em contexto de excepcionalidade por Isolamento Social Preventivo (ASPO) e Obrigatório (Decreto Presidencial n. ${ }^{\circ}$ 297/2020) face à pandemia COVID-19 são atípicas e complexas. Portanto, esta pesquisa busca analisar experiências de aprendizagem virtual que possibilitem o planejamento da comunicação educacional nos processos de ensinoaprendizagem; e, ao mesmo tempo, identificar as perspectivas e expectativas futuras sobre um sistema educacional turbulento e hipermídia. Para atingir os objetivos, um questionário aleatório foi aplicado a 194 alunos dos níveis de ensino fundamental, médio e superior / universitário da Província de Córdoba (Argentina). A partir dos dados coletados, as oportunidades de melhoria são evidentes, bem como os obstáculos a superar; Além disso, a continuidade dos problemas pré-existentes se aprofunda a partir da pandemia e surgem novas questões sobre como gerar uma educação comprometida com o desenvolvimento integral das pessoas e das sociedades. Uma educação com consciência das transformações do meio ambiente e da evolução tecnológica, mas ao mesmo tempo voltada para as pessoas, suas liberdades e potencialidades. Ouvir o que dizem os jovens protagonistas do sistema educativo é um primeiro passo para se conseguir uma educação que, sem esquecer o passado, habite o seu tempo e avance na construção da sociedade que cada um merece.

Palavras-chave: Educação, Tecnologia, Comunicação, COVID 19

\section{Introducción}

Según datos de la Organización de las Naciones Unidas para la Educación, la Ciencia y la Cultura (UNESCO), más de 14 millones de estudiantes en Argentina no pueden asistir a clases presenciales debido al Aislamiento Social Preventivo y Obligatorio decretado a causa de la pandemia de COVID-19. La interrupción del ciclo educativo recaló con fuerza en las instituciones formativas, sus docentes y estudiantes provocando una modificación obligada de las estrategias de enseñanza-aprendizaje. Las experiencias educativas se vieron inmersas en un contexto en donde la virtualidad y el uso de las Nuevas Tecnologías de la Información y Comunicación (NTICs), tomaron el protagonismo.

La posibilidad de documentar los impactos producidos por este contexto educativo turbulento desde la experiencia de sus protagonistas habilita el reconocimiento de las características de la experiencia de los estudiantes en los entornos virtuales y su relación con las herramientas utilizadas, con el proceso educativo y consigo mismos. El trabajo de investigación espera también describir las oportunidades de transformación y mejora hacia un futuro post pandemia en el que la planificación estratégica de la comunicación educativa pueda aportar valor al sistema educativo en los actuales ecosistemas hipermediáticos. 
En definitiva, conocer la experiencia de aprendizaje de los y las estudiantes en un contexto intensivo de comunicación mediada digitalmente, permite desarrollar una planificación estratégica de la comunicación educativa para acortar la brecha, que según Uranga (2008), separan la educación que tenemos de la que es necesaria. Las brechas hacia la comunicación educativa deseada se entienden como espacios donde la acción planificada puede ir superando la contemplación de los problemas, hacia la elaboración de soluciones concretas en situaciones específicas.

La presente investigación forma parte de dos estudios exploratorios sobre la experiencia educativa desde la perspectiva docente y estudiantil realizados por el equipo de investigación "Experiencias de Comunicación Transmedia Social/Educativa", de la Facultad de Ciencias de la Comunicación de la Universidad Nacional de Córdoba (Argentina), con el apoyo de la Mutual Conexión. Tuvo por objetivo general analizar las condiciones, prácticas y experiencias de aprendizaje virtual en tiempos de confinamiento.

Respecto a los objetivos específicos, se procuró: 1) determinar las condiciones de acceso a las tecnologías para el cursado virtual; 2) analizar las características y valoración de las herramientas y la experiencia de aprendizaje virtual; y 3) identificar perspectivas y expectativas a futuro sobre el aprendizaje virtual.

\section{Marco referencial}

Atravesamos un tiempo de acelerados y profundos cambios tecnológicos y culturales que modifican las lógicas de acceso al conocimiento. En ese contexto, el confinamiento obligatorio provocado por la pandemia del COVID-19, precipitó procesos en el ámbito educativo que estaban muy lejos de su maduración para un desarrollo eficaz. Se hace necesario repensar de manera estratégica, en mundo que ya es otro, la relación con el conocimiento y a su vez con la educación en todos los niveles. Así, desde una perspectiva integradora, revisar algunas de las prácticas más arraigadas dentro del sistema educativo, permitirán profundizar algunas de las contradicciones observadas en dicho sistema. Dice Meirieu, citando a Henri Marion: “Volver activo al alumno es (...) invitarlo a comprometerse personalmente con sus aprendizajes y proponerle trabajar en forma concreta, componiendo, escribiendo, dibujando, actuando de todas las maneras que le permitan ejercer y probar sus fuerzas" (2016:31). En ese "volver activo al alumno", es posible y deseable que la tecnología se transforme en una aliada en los procesos de enseñanza-aprendizaje y no un obstáculo. La tecnología es una aliada en la educación si se piensa ya no como externalidad, sino como una condición que atraviesa las formas de percibir la experiencia del mundo. La tecnología digital y el móvil en particular definen en gran medida las interacciones de las personas en este tiempo y ha quedado en evidencia su utilidad en los procesos educativos durante esta virtualidad obligada. Eso conlleva la necesidad de garantizar el acceso tanto para docentes como para estudiantes, a las tecnologías que posibiliten la educación. 
Enseñar y aprender son procesos que contienen un sinnúmero de interacciones posibles entre los actores que intervienen en ellos. Decimos procesos porque entendemos que son diferenciados, si consideramos que enseñar y aprender no necesariamente ocurren simultáneamente. Esta afirmación tiene aún más sentido si pensamos en el ámbito educativo, en todos los niveles y en la heterogeneidad de las aulas que los caracteriza.

En ambos procesos subyace un modelo de comunicación a partir del cual se define el sentido que esa práctica tendrá tanto para docentes como para estudiantes. Numerosos autores como Freire (1986), Kaplún (2010), Martín-Barbero (2000), Huergo (2000), por nombrar sólo latinoamericanos, reflexionaron tempranamente sobre esta relación y la necesidad de abordarla desde la reciprocidad del diálogo. No obstante, más allá de las experiencias que se pudieron desarrollar bajo esa impronta, la crisis del modelo difusionista y transmisivo de comunicación/educación recién se pone en evidencia de manera manifiesta en la última década del siglo XXI. En efecto, es la profundidad del cambio tecnológico y cultural lo que marca la imposibilidad de continuar en una suerte de inercia con un modelo educativo que desde hace varias décadas presenta dificultades para atender a las necesidades y características de las nuevas generaciones de sujetos de la educación.

Señala Martín-Barbero (2000), que en cada modelo de enseñanza subyace un modelo de comunicación que determina no sólo las formas sino también el sentido que esa práctica adquiere tanto para las y los estudiantes como para sus docentes. En la transmisión unidireccional de conocimientos, que en ocasiones es necesaria, pero no extensible a todas las instancias de los procesos de enseñanza y aprendizaje, ni a todos los ámbitos y niveles educativos, subyace un modelo de comunicación difusionista, inspirado en el modelo matemático de transmisión de información. Pero un modelo es sólo eso, un modelo, que puede ser aplicado en casos específicos, pero no necesariamente puede replicarse con eficacia a situaciones de índole diversa.

Ante la ebullición de las redes sociales y virtuales -las cuales tienden a ser cada vez más descentralizadas y de más fácil acceso a la información-, estos modelos unidireccionales entran en crisis. El conocimiento ya no está en un solo lugar. La tecnología permite acceder a él desde múltiples plataformas y dispositivos. En ese contexto los saberes sólo admiten ser construidos a través del diálogo, de interacciones genuinas, superadoras de certezas que en este tiempo están resquebrajadas. Si hay nuevas formas de conocer, se impone revisar las formas de enseñar y de aprender. Y al mismo tiempo repensar las formas de comunicar. Como señala Martín-Barbero (2000: 17), hay que poder atender a la complejidad de la educación en nuestras sociedades:

(...) nada le puede hacer más daño a la escuela que introducir modernizaciones tecnológicas sin antes cambiar el modelo de comunicación que subyace al modelo escolar: un modelo predominantemente vertical, autoritario, en la relación maestroalumno, y linealmente secuencial en el aprendizaje. Meterle a ese modelo medios y tecnologías modernizantes es reforzar aún más los obstáculos que la escuela tiene para insertarse en la compleja y desconcertante realidad de nuestra sociedad. 
El uso excesivo de pantallas y redes virtuales se plantea con frecuencia como una de las razones posibles de las dificultades en la lecto-escritura de las y los estudiantes, así como en los niveles de atención y de interés en el trabajo áulico. Si bien puede haber algún grado de acierto en la afirmación, entendemos que no contempla la complejidad del avance tecnológico y sus implicancias profundas en la cultura y en las prácticas de los sujetos, en este caso los estudiantes. Por cierto, y en un sentido diverso, también se desarrollan experiencias que, aún desde una mirada crítica, ponen énfasis en aspectos que precisamente sí se pueden fortalecer en los procesos de enseñanza y aprendizaje, desde la utilización reflexiva y estratégica de la tecnología, tanto digital como analógica.

En este contexto, cobra un valor fundamental la planificación y ejecución de una comunicación educativa estratégica que requiere tener en claro cuáles son los resultados esperados de la intervención y cuál es el conjunto de valores que se sostendrán a lo largo del proceso. Exige conocer la situación actual de la educación; cuáles son los recursos con los que se cuenta para alcanzar ese objetivo; las características del contexto dentro del cual se opera para poder prever cómo este puede entorpecer o beneficiar el proceso educativo; así como los grupos sociales implicados. Si se desestiman estos factores la estrategia resultante no podrá brindar la solidez necesaria para gestionar adecuadamente los recursos y hacer frente a la incertidumbre.

\section{Metodología}

La presente investigación corresponde a un estudio de tipo exploratorio que, a través de un cuestionario realizado desde la plataforma Google, se propuso recabar información sobre las modalidades y experiencias educativas en en entornos virtuales, según la perspectiva de los y las estudiantes en el contexto de la pandemia por COVID 19.

El formulario se distribuyó y circuló de manera aleatoria desde el 9 de junio hasta el $1^{\circ}$ de julio de 2020 entre estudiantes de los niveles secundario, superior y universitario de la provincia de Córdoba (Argentina), con la intención de construir un relevamiento detallado de la experiencia desde el comienzo del aislamiento.

Respecto a las características de la muestra, de un total de 194 estudiantes encuestados, el 47,7\% realizan sus estudios en universidades públicas (en su mayoría cursando carreras pertenecientes a las ciencias sociales); el 44,3\% en escuelas secundarias públicas (con un 67\% realizando los últimos dos años de instituto); y el porcentaje restante lo componen personas que forman parte de instituciones universitarias privadas, terciarios y secundarios para adultos/as.

\section{Hallazgos}

\section{a) Condiciones de acceso a las tecnologías para el cursado virtual}

Cuando se consultó a los y las estudiantes si tenían experiencia previa utilizando espacios virtuales para el cursado de sus estudios, un 60,3\% indicó que era la primera vez 
y el restante $39,7 \%$ que ya había usado algún tipo de plataforma virtual para el aprendizaje. Para la mayoría, entonces, la experiencia del aprendizaje virtual es una novedad, aunque, es importante señalar que los y las estudiantes de manera informal y no sistematizada empleaban previamente diferentes herramientas en línea para complementar sus estudios presenciales, antes del aislamiento, por ejemplo: Whatsapp para comunicarse y organizarse con sus compañeros, YouTube para encontrar videos relacionados a los temas que estaban estudiando y procesadores de texto digitales como Word o Google Drive para la redacción de sus trabajos.

La novedad se encuentra reflejada en la canalización sistematizada y exclusiva de todo el proceso de aprendizaje a través del entorno virtual. Después de la cuarentena y con el regreso a las aulas, probablemente, la mayoría de los estudiantes contará con una experiencia valiosa con respecto al cursado virtual y la utilización de las tecnologías digitales para la gestión de su proceso de aprendizaje.

Figura 1

\section{¿Es la primera vez que utilizás un espacio virtual para el cursado de tus estudios?}

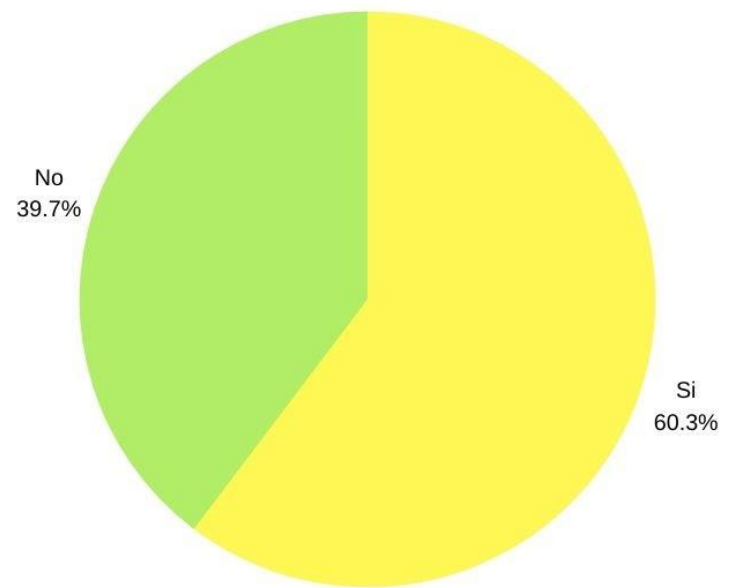

\section{Elaboración propia}

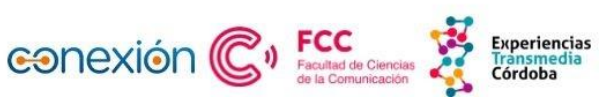

Con respecto al tipo de dispositivo que los y las estudiantes utilizan, el teléfono celular es el más empleado (86,6\%), seguido de las Notebooks o Netbooks $(57,7 \%)$ y las computadoras de escritorio (43,8\%). El alto uso del celular en los estudios apunta a un uso complementario de otros dispositivos como Notebooks, Netbooks o PCs.

En este punto, se evidencia el elevado diseño y performance que han logrado los celulares en razón del avance y la mejora continua de las empresas fabricantes de estos dispositivos y de software, permitiéndoles igualar y mejorar las capacidades de una computadora personal. Su carácter móvil lo convierte en una herramienta omnipresente y de uso variable, que combina la inmediatez de la conexión a internet con la integración de todas las herramientas del entorno virtual. De esta manera, habilita a los y las 
estudiantes la posibilidad de atender las actividades relacionadas a sus estudios en cualquier lugar y momento, involucrando las capacidades de operación múltiple que las personas han alcanzado por efecto de las transformaciones en el ecosistema tecnológico y la dinámica social.

Figura 2

\section{¿Con qué dispositivos tecnológicos contás para realizar tus clases virtuales?}

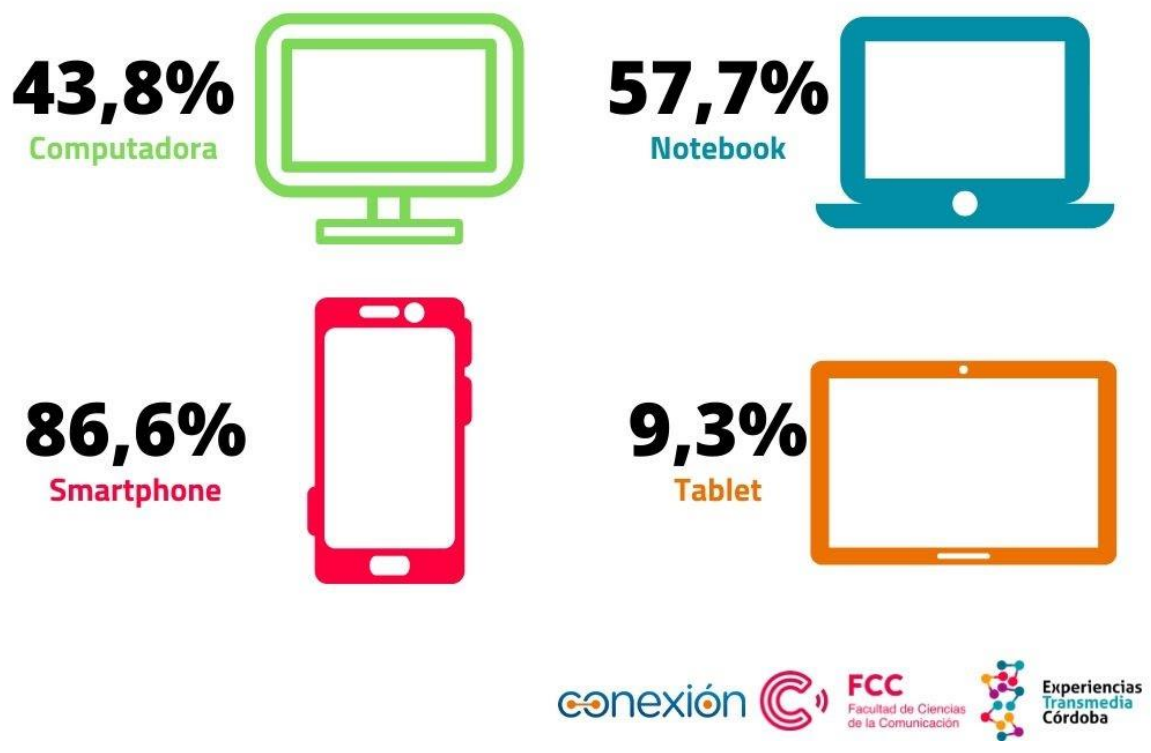

\section{Elaboración propia}

En lo referido al tipo de conexión que utilizan los y las estudiantes para conectarse a internet durante el desarrollo del proceso educativo, los resultados muestran conformidad con la pregunta anterior, acerca del tipo de dispositivo empleado en donde predominaba el uso de dispositivos móviles, puesto que en su mayoría $(89,2 \%)$, se conectan a internet a través de redes WiFi inalámbricas. Muy por detrás $(27,3 \%)$, le sigue el uso de paquetes de datos móviles $3 \mathrm{G}$ y $4 \mathrm{G}$ para la conexión desde el celular o el uso compartido de internet. Los datos móviles provistos por las compañías de telefonía celular suelen manejar precios elevados puesto que se pagan individualmente por línea y normalmente tienen límites en la cantidad de gigabytes que se pueden consumir, por lo que suelen ser utilizados para no perder la conexión en los casos en los que no se dispone de conexión WiFi o cuando esta anda lenta o tiene problemas. Dentro del grupo de respuestas, también entra un $16 \%$ de estudiantes que utilizan internet a través de cable alimentado, por lo general, por conexiones a computadoras de escritorio. Este tipo de conexiones destaca por ser más estable y veloz, ya que con el internet inalámbrico siempre existe el riesgo de perder la conexión y que, por ejemplo, no se pueda terminar de entregar un trabajo o se pierdan los avances y no se guarde el trabajo realizado. 
Figura 3

¿Con qué tipo de conexión contás?
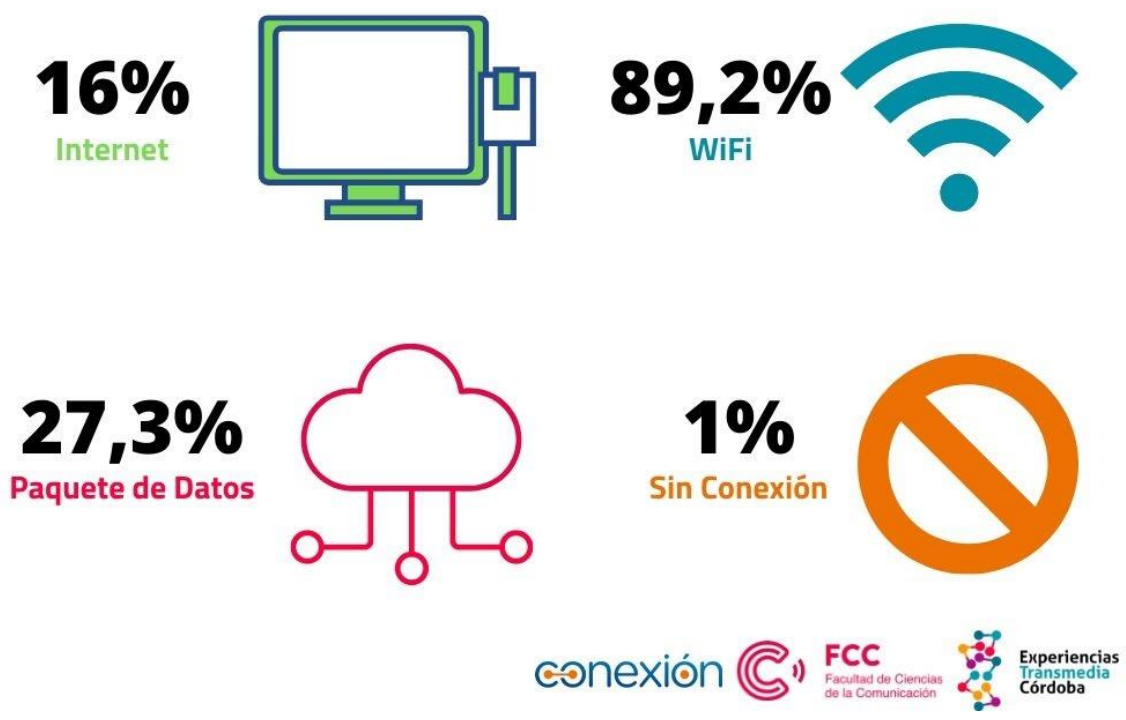

Elaboración propia

\section{b) Características y valoración de las herramientas y la experiencia de aprendizaje virtual}

A continuación, se desarrollan los resultados de la categoría "Características y valoración de las herramientas y la experiencia de aprendizaje virtual". La misma contempla una valoración numérica en la escala del 1 al 5, siendo 5 el puntaje acorde a la calificación más alta y, por lo tanto, positiva.

Figura 4

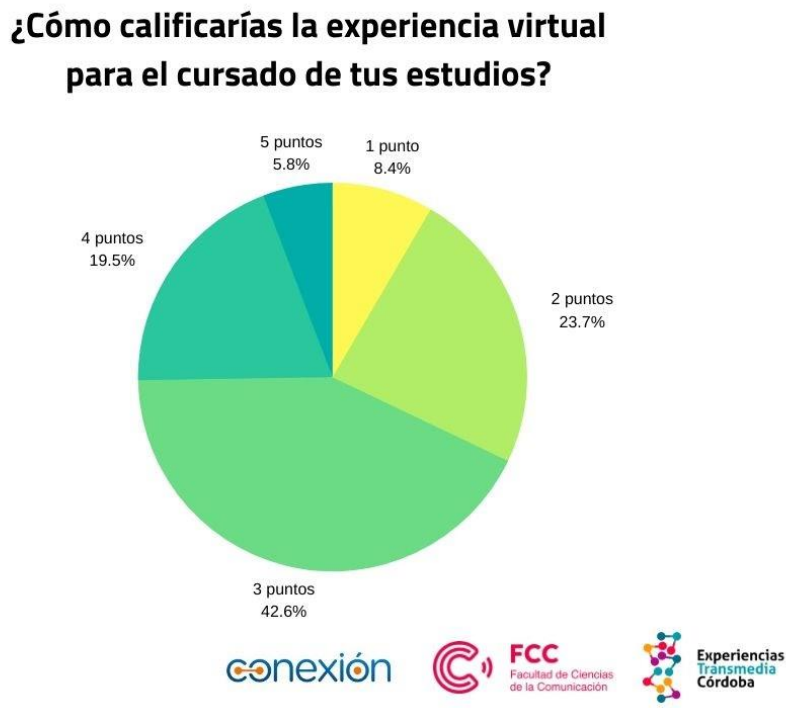

Elaboración propia 
Un 42,6\% de los encuestados calificó con 3 puntos la experiencia, seguido por las puntuaciones $2(23,7 \%), 4(19,5 \%), 1(8,4)$ y $5(5,8 \%)$. Tomando la calificación 3 como parámetro intermedio se observa que casi un tercio de la muestra tiene una valoración por debajo de 3 y un cuarto por encima de ese mismo valor.

Se deduce, entonces, por el agrupamiento de las calificaciones bajas, que la insatisfacción en la experiencia virtual estaría presente en uno de cada 3 estudiantes y que solo un cuarto del total considera su experiencia de manera satisfactoria, es decir, superando la calificación media (3).

Para dotar de especificidad a este puntaje, es necesario trasladar la graduación de los datos arrojados a las respuestas de las preguntas acerca de la experiencia y las sensaciones en el proceso de aprendizaje en entornos virtuales.

La administración del tiempo, por ejemplo, es un factor fundamental para comprender las valoraciones graduales previas. Su manejo se ha transformado a partir de la inserción de herramientas y recursos digitales en el proceso de aprendizaje. La variedad de dispositivos conectados modifica la rutina diaria de los estudiantes. En primer lugar, es posible estar conectado en cualquier lugar; por otra parte, esa omnipresencia afecta la dimensión temporal, incrementándose la fragmentación del devenir cotidiano. Este nuevo ordenamiento diario está definido por "burbujas de ocio" emergentes, la deriva en la multitarea y la simultaneidad de interfaces orientadas a diferentes fines.

Figura 5

\section{¿Cuánto tiempo promedio dedicás al aprendizaje virtual?}

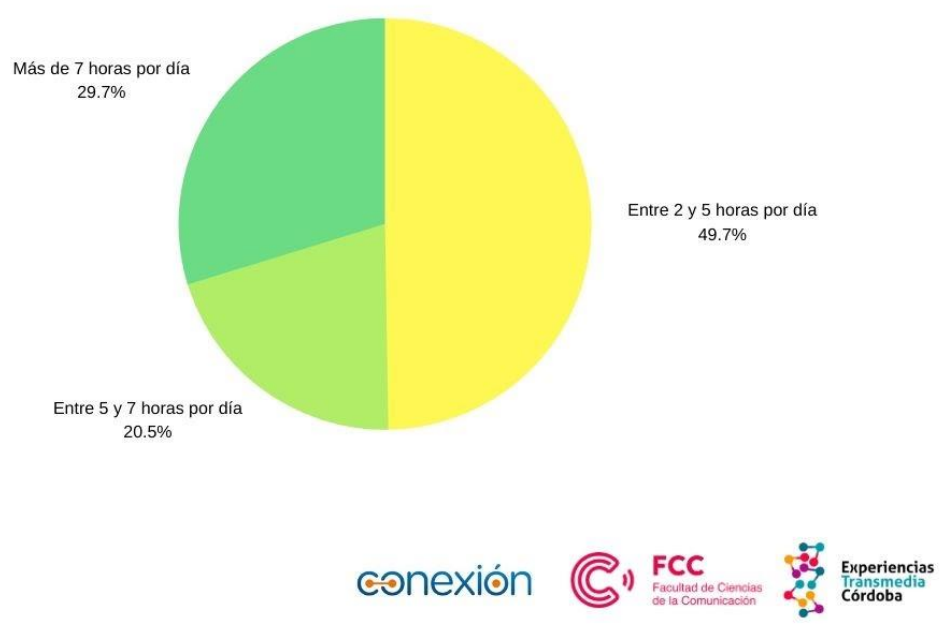

\section{Elaboración propia}

Casi la mitad de los y las estudiantes $(49,7 \%)$ respondieron que dedican al aprendizaje virtual entre 2 y 5 horas por día. Un tercio supera las 7 horas. Un $20 \%$ estudia entre 5 y 7 horas por día. Un poco menos de la mitad (47,7\%) señala que esta modalidad le demanda más tiempo que la presencialidad. Apenas un $16 \%$ considera lo contrario, es 
decir, que es menor el tiempo requerido. El 35,4 \% ha señalado que, a veces, esta modalidad le demanda más tiempo.

La lectura de estos porcentajes debe tener en cuenta que los bloques horarios consignados no son necesariamente continuos, es decir, están interrumpidos. Estas pausas se deben al uso de segundas pantallas (se utiliza otro dispositivo al mismo tiempo para otra tarea o función como se ve en el apartado de dispositivos utilizados), y/o a actividades cotidianas en el hogar. La pandemia ha condicionado los horarios de trabajo, por lo tanto, no está garantizado que los bloques de tiempo sean independientes y continuos.

\section{Figura 6}

\section{¿Creés que aprender en la virtualidad, te lleva más tiempo que la modalidad presencial?}
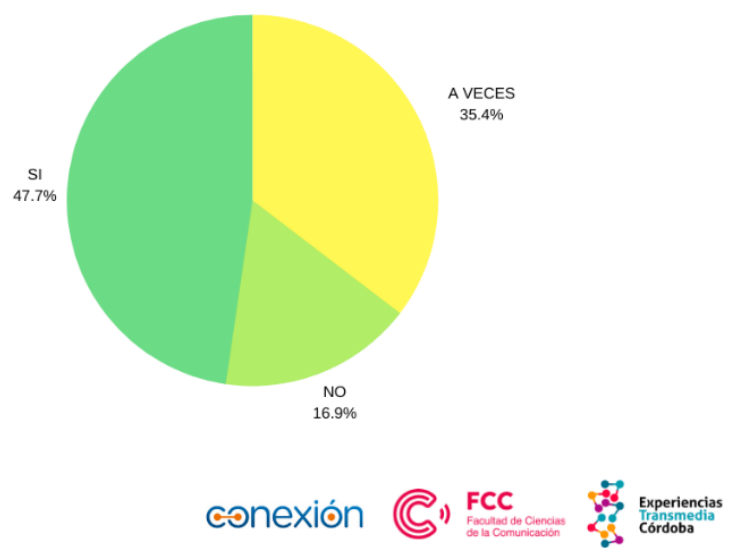

\section{Elaboración propia}

Otro aspecto para considerar que permite dotar de significado a la escala de puntuación inicial es la frecuencia de uso y la calificación de los recursos, herramientas y plataformas que se utilizan en estas instancias de educación en la virtualidad.

Figura 7

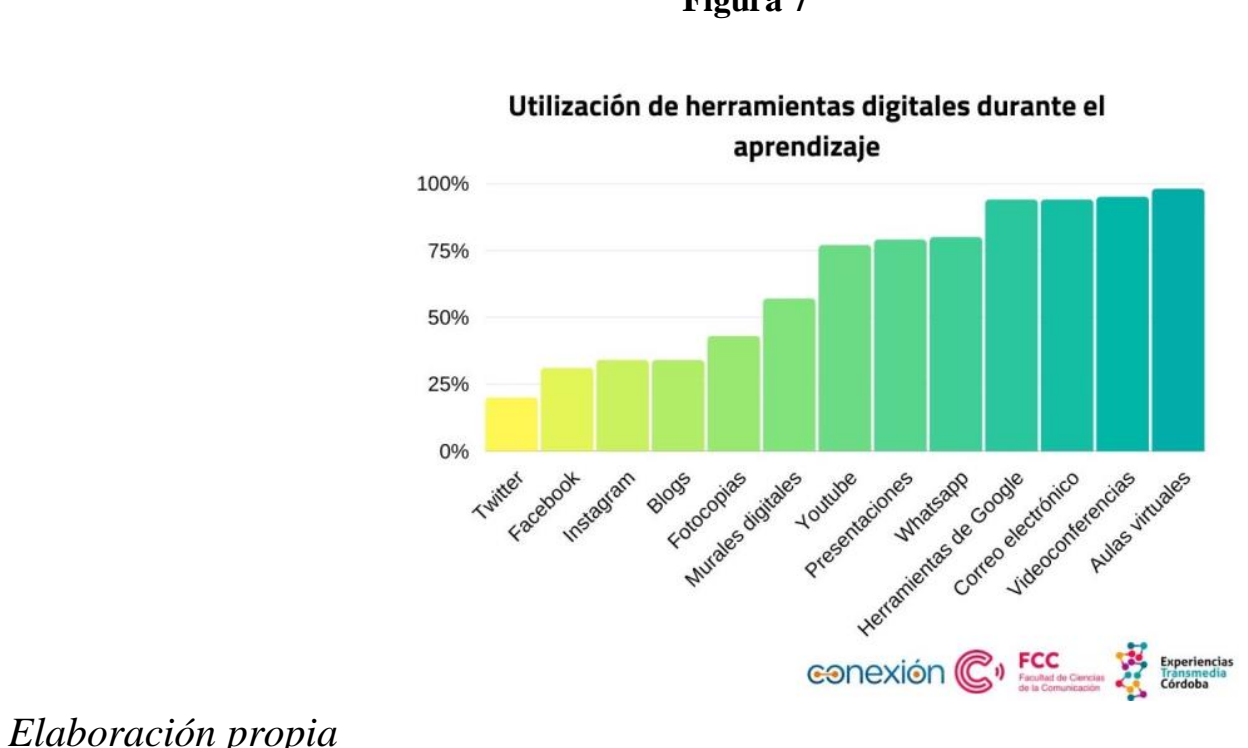

Elaboración propia 
Los resultados de la encuesta muestran un bajo porcentaje de utilización de las redes sociales en el ámbito educativo. Sólo un 32\% de las y los encuestados utiliza Facebook, 35\% utiliza Instagram y 21\%, Twitter. Las herramientas más empleadas son las aulas virtuales (98\% de los estudiantes las usa) con una valoración positiva del $65 \%$ y una negativa del 13\%. Las instituciones, las y los educadores, en este aspecto, concentraron el flujo central de las prácticas pedagógicas en las aulas virtuales en donde tienen la ventaja del control, centralizando diferentes aspectos del proceso educativo como la comunicación con el estudiantado, el desarrollo de sus clases, la asignación y recepción de tareas.

Las herramientas digitales más utilizadas después de las aulas virtuales son las videoconferencias. Estas tienen un porcentaje de uso del $96 \%$, y se presentan como el complemento de las aulas virtuales para suplir el dictado de clases presenciales, sobre todo porque facilitan la interacción inmediata con el estudiantado. La valoración de estas herramientas es un $57 \%$ positiva y un $19 \%$ negativa.

Otras herramientas que han logrado gran popularidad en esta situación de aislamiento social son las que ofrece Google, como Drive, las Presentaciones y Documentos, que pueden ser empleados para crear textos en línea o tablas. Un $94 \%$ de las y los estudiantes las usan y un $75 \%$ las evalúa positivamente, mientras que sólo un $6 \%$ las evalúa negativamente. Según los resultados de la encuesta, estas herramientas han sido valoradas por las y los estudiantes como las mejores para su utilización en el ámbito educativo.

\section{Figura 8}

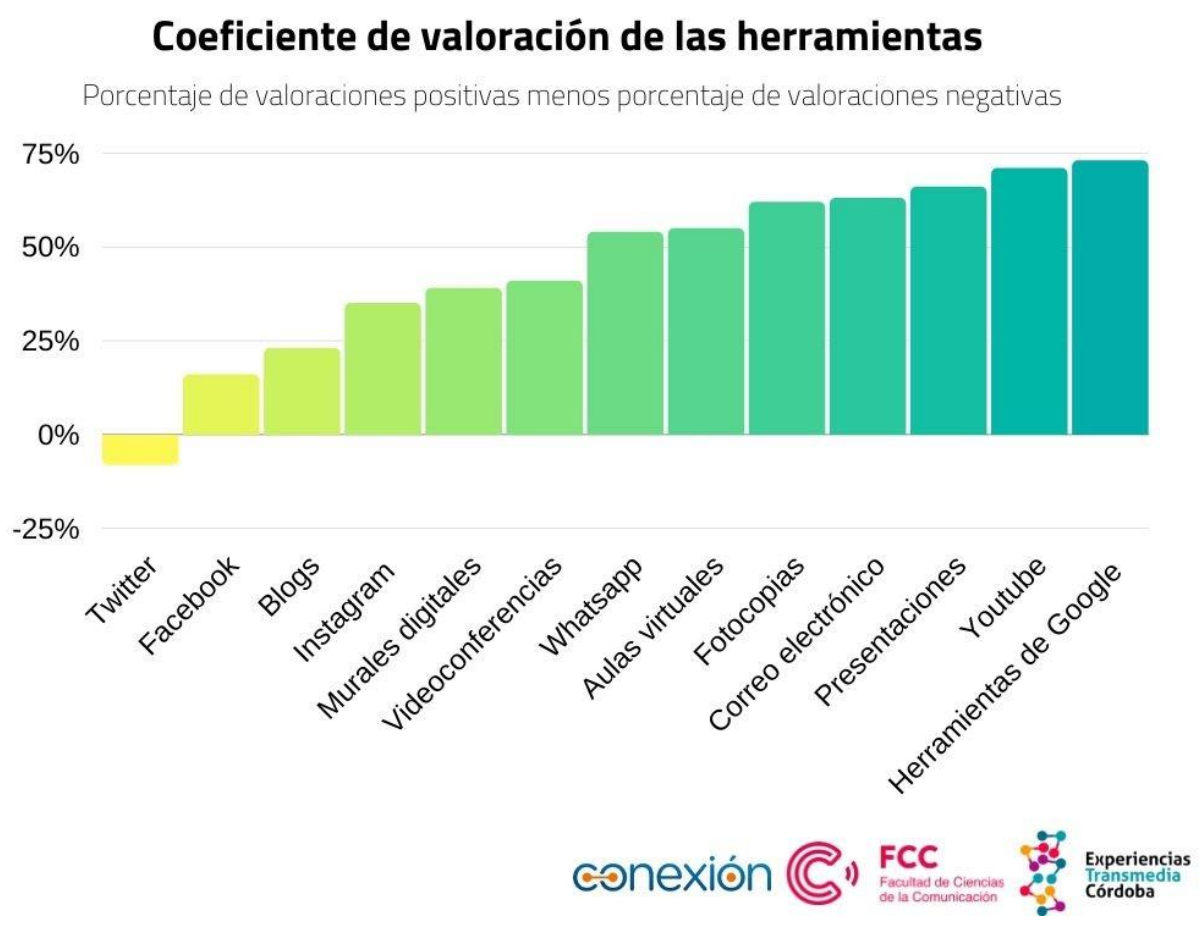

Elaboración propia 
Después de haber calificado las diferentes herramientas que las y los estudiantes están empleando en el aprendizaje virtual, se les pidió en la encuesta que mencionen qué es lo que más valoran de las herramientas que calificaron positivamente. A través de esta pregunta se obtuvo un conjunto de categorías consideradas valiosas, y que deben atenderse para pensar en una estrategia de educación virtual al momento de incorporar herramientas digitales al proceso de aprendizaje. Estas categorías aluden a las características que debería tener el proceso de aprendizaje para acercarse a la mejor experiencia posible, según la consideración de quienes aprenden.

- Usabilidad. Se refiere a la facilidad de uso de las herramientas para la satisfacción de los objetivos de sus usuarios. Es una de las cualidades más valoradas por los y las estudiantes al momento de medir las herramientas informáticas con las que desarrollan sus estudios en la modalidad virtual. Algunos atributos que están incluidos dentro de esta categoría son la efectividad, la baja presencia de errores, el bajo nivel de esfuerzo que es necesario realizar para completar una actividad, la facilidad que involucra el acceso a los contenidos, la navegación y el rápido aprendizaje de la herramienta, así como la comodidad para su uso. Google Drive y Class Room son algunas de las plataformas más valoradas por los estudiantes por su facilidad de uso y dentro de estas plataformas, la organización, la simpleza de su manejo y la posibilidad de entregar los trabajos de forma sencilla.

- Rapidez. Es otra de las cualidades más valoradas para el aprendizaje virtual. La rapidez con la que los y las estudiantes pueden conectarse, comunicarse, realizar entregas de trabajos, descargar o visualizar material y cumplir sus objetivos en las plataformas tiene un gran impacto en la satisfacción experimentada. Acostumbrados a la inmediatez de la comunicación, la demora es un factor disruptivo que es percibido con malestar. La rapidez de las herramientas está relacionada con otros factores como la velocidad del internet, el dispositivo desde el cual se accede y la usabilidad de la plataforma. En este sentido apuntan varias valoraciones positivas y negativas hacia herramientas como Zoom para el dictado de clases virtuales por videoconferencia; ya que en las clases con muchos participantes y con velocidades de internet bajas, la herramienta suele ralentizarse y la experiencia se ve deteriorada. Sin embargo, la videoconferencia también es valorada positivamente por permitir una respuesta sincrónica a las consultas por parte de los y las docentes, sin requerir espera (como sería el caso de una pregunta por e-mail, por ejemplo).

- Formato audiovisual. El contexto de aislamiento y la necesidad de encontrar alternativas para el aprendizaje a distancia, terminó por sacar al sistema educativo de su estado de resistencia a la "ubicuidad" que posibilita la sociedad conectada tecnológicamente en la cual se estaban 
desarrollando las y los estudiantes por fuera de las aulas. De forma apresurada y traumática, educadores y gestores educativos tuvieron que adentrarse en el uso del lenguaje audiovisual y las tecnologías digitales. Clases filmadas y subidas a YouTube y Videoconferencias a través de Zoom son ahora las modalidades más parecidas a la educación tradicional. La posibilidad de volver a ver y escuchar a los y las docentes, es una de las características mejor valoradas y esto tiene un componente tanto de añoranza de una normalidad ausente, como de aprecio por las características plenas del entorno digital. Pausar el video para tomar notas, volver a repetirlo cuando no se entendió algo, apagar la computadora y retomar el proceso luego en el momento en que había sido pausado, son características propias del lenguaje audiovisual que potencian el proceso educativo y se acomodan a las necesidades particulares de la autogestión que cada estudiante hace de su propio proceso de aprendizaje. Las videoconferencias agregan la inmediatez y la presencialidad de una comunicación social audiovisualmente mediada habilitando un contacto directo con el personal docente para evacuar las dudas en el momento mismo en que surgen. El formato audiovisual en vivo que permite la interacción con las y los docentes, y el video subido a la red y que puede ser consultado en cualquier momento son algunas de las herramientas más valoradas para obtener una experiencia de aprendizaje más completa gozando a la vez de las ventajas de la digitalidad como de la semejanza con la educación tradicional.

- Interacción con compañeros y profesores. El contacto con profesores y estudiantes es otra de las características mejor valoradas en las herramientas utilizadas para el aprendizaje virtual. Se verifica como en un contexto de aislamiento, aquellas herramientas que mejor permitan reducir la distancia y acercarse a los otros son consideradas más valiosas. Las características de esta interacción, sin embargo, son variables de acuerdo con cada plataforma y algunas cumplen sus objetivos mejor que otras. Las videoconferencias en vivo son evaluadas positivamente porque permiten realizar consultas a los profesores que pueden ser respondidas de forma inmediata y los grupos de Whatsapp permiten la comunicación con los compañeros y el trabajo en equipo, sin embargo en estos últimos el exceso de comunicación puede volverse un problema y la falta de una direccionalidad y la cantidad de interactores cada uno haciendo uso irrestricto de su propia libertad e idiosincrasia pueden ser un obstáculo para la eficiencia del proceso de organización del aprendizaje. Cada plataforma tiene un juego de posibilidades y limitaciones que configuran su idoneidad para algunos procesos, mientras que para otros se muestran débiles o generan más inconvenientes que los que solucionan. Esto relata la importancia de detectar la potencialidad de cada interfaz, para poder aplicarla a la solución del objetivo adecuado. Es en este aspecto, donde se 
hace necesario que las y los educadores como gestores educativos, conozcan en profundidad las características de las herramientas que conforman el entorno digital de aprendizaje.

- Permanencia de los contenidos. "Que te permite ver las clases una y otra vez hasta que entiendas", es una de las expresiones más usadas para destacar las ventajas de la permanencia de los contenidos que las herramientas digitales habilita. La posibilidad de repetir el video y repasar las clases con la tranquilidad de saber que el contenido cargado en internet escapa a la fugacidad del tiempo, contribuye a la autogestión del aprendizaje. A su vez, alivia el trabajo docente, que ya no está ligado a la repetición de explicaciones; pudiendo ser complementado, el formato audiovisual, con otras interfaces que permitan atender las consultas particulares de sus estudiantes. El contenido alojado en internet es un recurso valioso para el aprendizaje, pero es tan vasto que la adecuada navegación y el criterio para no perderse y diferenciar lo útil de lo accesorio y de lo que es directamente falso, se ha convertido en una habilidad imprescindible para operar de forma adecuada en el ambiente digital. Como en cualquier espacio, hay que saber hacia dónde nos dirigimos para poder avanzar con certezas en un ambiente saturado de información que no siempre es confiable o segura. En este sentido cobra importancia la figura del docente como curador de contenidos y guía del aprendizaje, siendo necesario que no sólo se eduque en la materia o la rama del conocimiento correspondiente, sino también se brinden las herramientas necesarias para que las y los alumnos puedan llevar adelante el proceso de aprendizaje de forma eficaz y criteriosa.

- Autogestión de tiempos, espacios y contenidos. En el conjunto de respuestas al cuestionario, se valora en gran medida la posibilidad de autogestionar el propio proceso de aprendizaje que ofrecen las herramientas digitales. En este aspecto, se destaca el manejo del tiempo propio y la libertad, con respecto a las ataduras a un horario y un espacio fijo de cursado. La autogestión del aprendizaje tiene el potencial de fomentar actitudes y cogniciones conducentes al cumplimiento activo de los objetivos académicos del estudiantado. Este enfoque pone en el centro al alumno y a la alumna desafiando su capacidad para cumplir con las metas educativas gestionando los recursos y su propio progreso. La alta valoración de la autogestión del proceso educativo encaja con la tendencia general al empoderamiento de las personas en los entornos digitales, que se encuentran cada vez más acostumbradas a disponer de contenidos y servicios según sus propios términos, pudiendo por ejemplo personalizar las noticias que les llegan según sus intereses o consumir el entretenimiento que prefieran, en el dispositivo que elijan, en el momento en que así lo quieran. 
Como complemento, también se preguntó qué es lo que evalúan como inadecuado o dificultosos en las herramientas evaluadas. Mediante este interrogante se obtuvo un conjunto de categorías que deben tenerse en cuenta al momento de pensar una estrategia de educación virtual y elegir las herramientas digitales pertinentes.

Figura 9

\section{¿Qué es lo que te parece inadecuado o dificultosos de las herramientas que evaluaste negativamente? (Respuestas principales)}

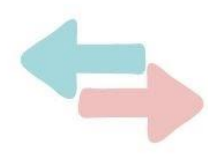

$12,4 \%$

Bajos niveles de feedback

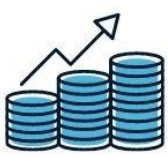

$9,4 \%$

Limitaciones comerciales

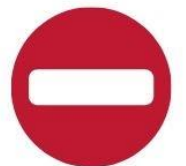

$9 \%$

Dificultosa para el trabajo individual o grupal

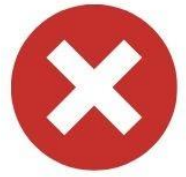

$8,5 \%$

No presentan

utilidad

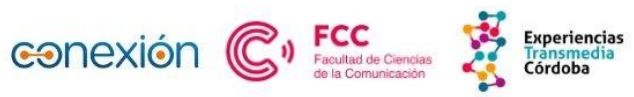

\section{Elaboración propia}

Las y los estudiantes señalan que lo más inadecuado o dificultoso de las herramientas utilizadas, es el bajo nivel de retroalimentación (12,4\%). Las respuestas oscilan entre limitaciones propias de la plataforma (vinculadas al diseño de la interfaz), y la escasa respuesta o interacción por parte del equipo a cargo de las cátedras o asignaturas.

Un 9,4\% de los encuestados encuentra dificultades técnicas o limitaciones de licencia comercial en las herramientas, es decir, funciones bloqueadas a las que se accede mediante membresía o sesión de datos. Un número menor dentro de este grupo advierte la presencia de contenidos dañados o ilegibles, en especial en documentos digitalizados.

Un porcentaje similar (9\%), indica que las herramientas utilizadas no satisfacen técnicamente las necesidades para su trabajo individual o la interacción en grupos.

Asimismo, el 8,5\% pone en duda la utilidad de estas herramientas en la trayectoria educativa. El 8,1\% de los encuestados manifiesta estar conforme con el uso de las herramientas. Otro 5,6 \% señala que es inadecuada la estrategia elegida en la vinculación plan de trabajo - herramienta elegida. 
Figura 10

\section{¿Qué emociones te genera el aprendizaje mediado por la tecnología? Seleccioná las tres más frecuentes.}
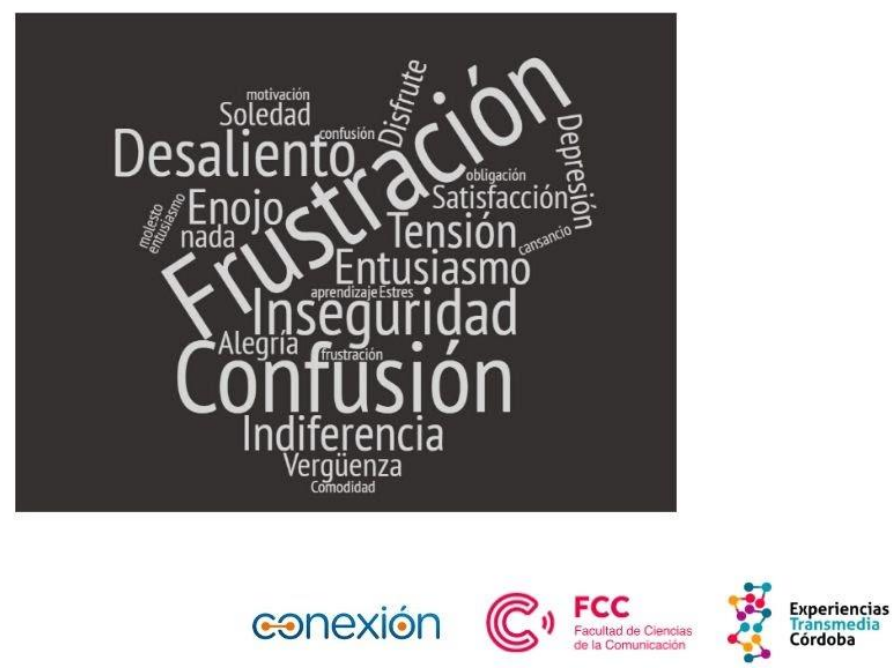

\section{Elaboración propia}

Para detectar emociones generadas por el uso mediado de la tecnología se cuantificó el campo semántico de las respuestas. Como emociones positivas y pretendidas en todo proceso de aprendizaje, se encuentran el entusiasmo $(4,8 \%)$ y la curiosidad $(12,1$ $\%)$. Sin embargo, es mayor el espectro de emociones menos deseadas: la más frecuente es la frustración (17.6\%), con un total de 80 menciones entre 196 respuestas, y le sigue la confusión (15,2\%) con 69 menciones. También se señalan: el aburrimiento (12,3\%), la ansiedad (8,6 \%), la incomprensión (6,6 \%), la inseguridad (5,5\%), el desaliento $(5,3$ $\%)$, la tensión $(4,8 \%)$ y el enojo (4\%).

\section{Figura 11}

\section{¿Qué emociones te genera el aprendizaje mediado por la tecnología? Seleccioná las tres más frecuentes.}
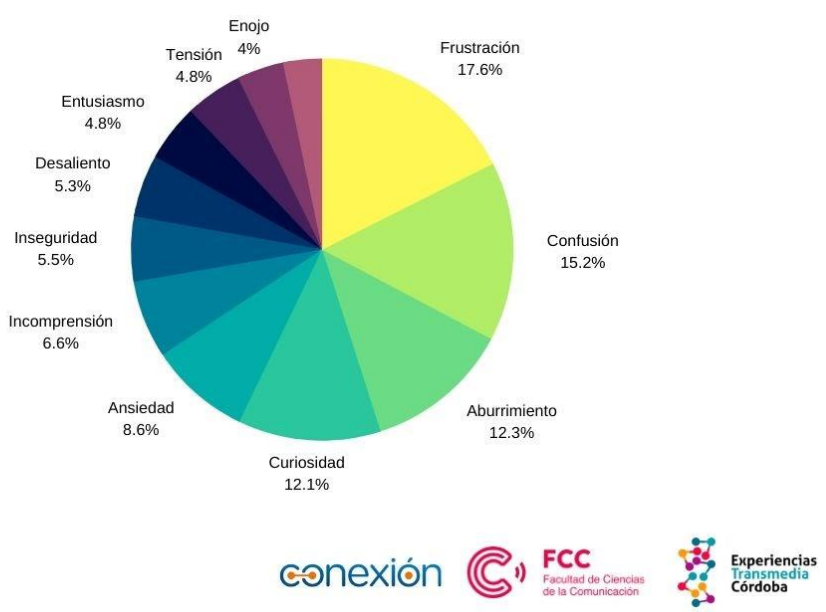

Elaboración propia 
Este abanico de emociones está matizado por las "ventajas" que se le asignan a la modalidad virtual.

En primer lugar, hay valoraciones enlazadas al devenir de la sociedad en red: un $34,8 \%$ considera que la modalidad digital es acorde al actual desarrollo tecnológico en comparación a la educación tradicional. Esta respuesta, con claros vínculos con el presente, se relaciona a la necesidad imperante de un mediano y largo plazo: un 12,8 \% señala que esta forma de aprendizaje prepara mejor para el futuro profesional.

El tiempo vuelve a estar presente en las valoraciones: ventaja en el menor tiempo consumido $(22,7 \%)$, la comodidad que genera la supresión de los traslados $(8,6 \%)$, la ductilidad de los tiempos de cursado $(7,3 \%)$ y la agilidad que aportan ciertas herramientas digitales para la interacción con el docente $(2,8 \%)$.

Figura 12

\section{¿Cuáles son las principales ventajas de esta forma de aprender?}

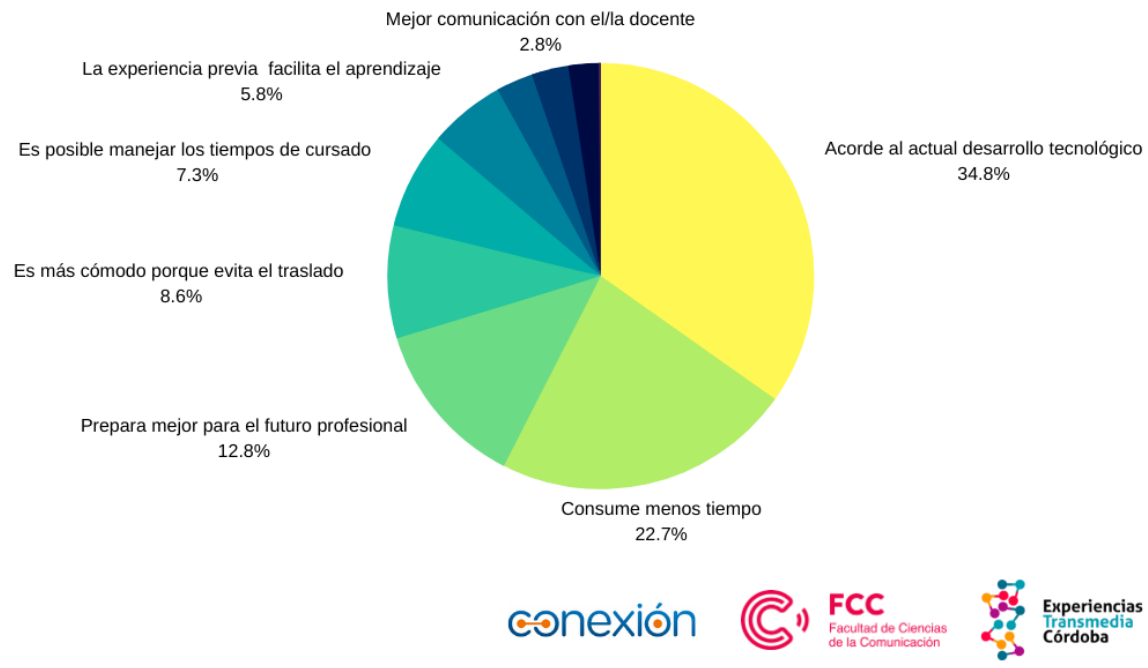

\section{Elaboración propia}

Respecto a las principales dificultades del aprendizaje en modalidad virtual, se señalan falta de apoyo del docente $(24,9 \%)$, seguido de la falta de información $(15,5 \%)$. En el plano material, se destacan la falta de espacio adecuado $(13,5 \%)$, y exiguo equipamiento $13,3 \%$. Esta escasa preparación del entorno de trabajo está vinculada a la intempestiva implementación de la virtualidad. Otra dificultad se relaciona con la concreción de tareas y actividades de manera individual (13\%), una situación vinculada a la tradicional cooperación entre estudiantes en el ámbito presencial, no afianzada totalmente en la virtualidad. La falta de conocimiento en el uso de la herramienta alcanza al $8,8 \%$ de los y las estudiantes. 
Figura 13

\section{¿Cuáles son las principales dificultades de esta forma de aprender?}

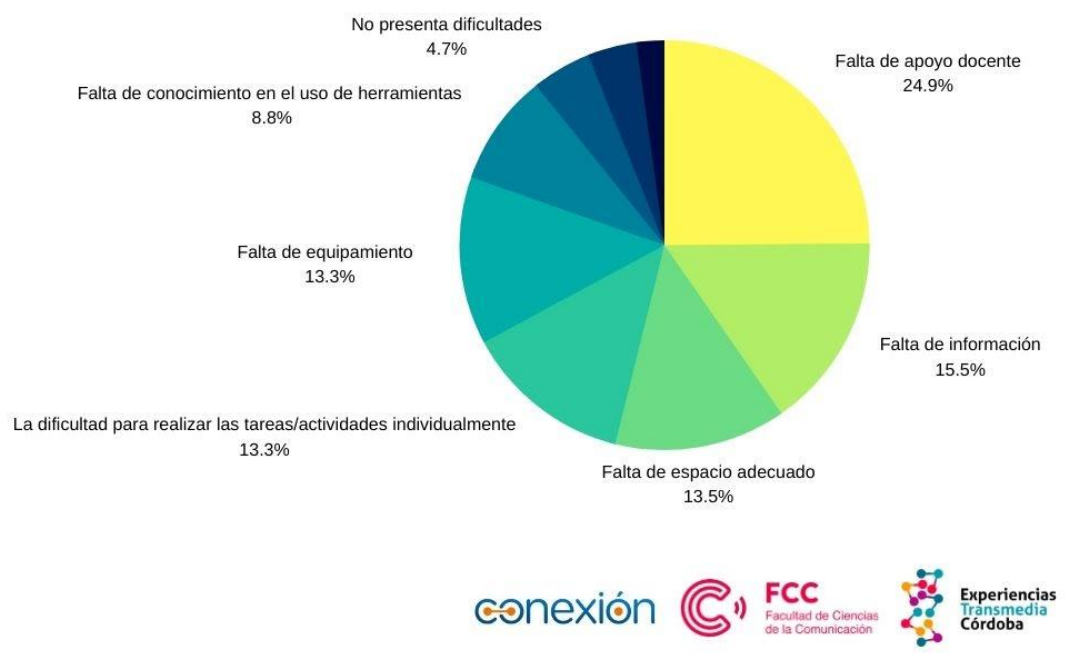

Elaboración propia

\section{c) Perspectivas a futuro sobre el aprendizaje virtual.}

Para finalizar el estudio, se pretendió analizar los cambios surgidos en los procesos de enseñanza y aprendizaje en tiempos de pandemia COVID-19 que, desde la mirada de estudiantes, puedan darse y/o mantenerse a futuro. Para ello, se les preguntó si consideraban que el cambio en las formas de enseñar y aprender en esta emergencia dará lugar a modificaciones más profundas en el sistema educativo. Sólo el 10,3\% de las personas encuestadas asegura que no habrá cambios, y casi el 90\% afirmó que sí $(46,9 \%)$ o tal vez $(42,8 \%)$.

Figura 14
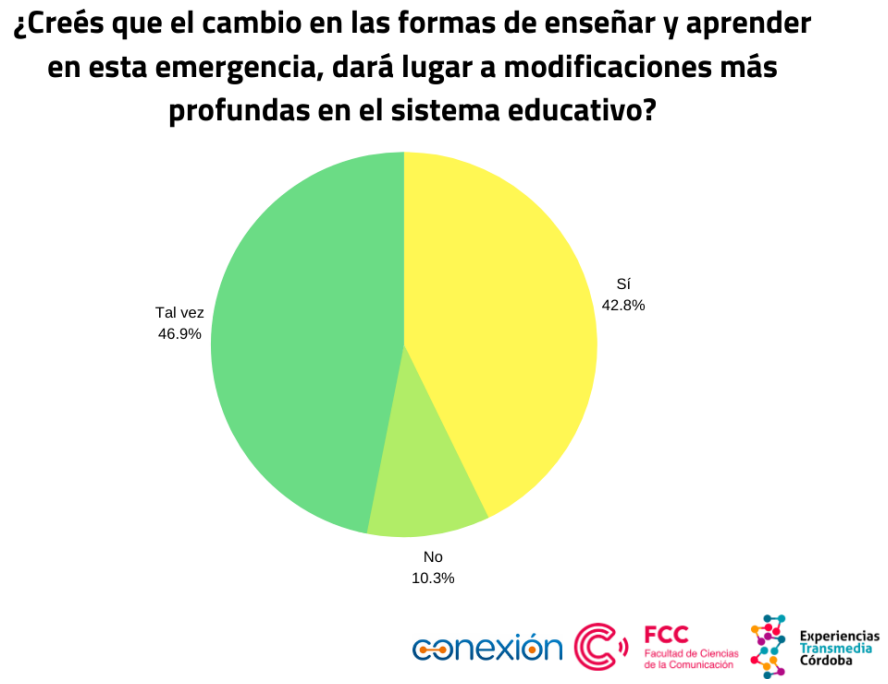

Elaboración propia 
A su vez, se procuró conocer cuáles de estos cambios, aspectos o herramientas de la educación en entornos mediados por la tecnología y la virtualidad, los y las estudiantes consideran que deberían mantenerse. Entre los resultados a esta pregunta de tipo abierta y cualitativa, se pueden extraer las siguientes conclusiones:

- Aula virtual: la gran mayoría de las y los estudiantes encuestados, manifestó que las aulas virtuales (específicamente se menciona a las plataformas "Classroom" y "Moodle"), presentan numerosos beneficios para el cursado entre los que se destaca un mayor nivel de organización, la posibilidad de contar con material de apoyo, la carga actividades y calificaciones, la disponibilidad de grabaciones de audios y videos de clases, los foros de debate, entre otros.

- Combinación entre clases virtuales y presenciales: si bien la mayoría apunta las ventajas de la virtualidad, un importante número de estudiantes remarca la necesidad de combinarla con la presencialidad y el contacto personal con sus docentes. Se proponen clases presenciales complementadas con clases de consultas virtuales, clases presenciales en streaming (retransmisión en directo) para quienes no hayan podido asistir, además de mantener el aula virtual como espacio de entrega de trabajos, calificaciones y depósito de grabaciones y archivos multimediales complementarios al cursado.

- Plataformas digitales: los y las estudiantes proponen mantener herramientas como Podcast (publicación digital periódica en audio o vídeo), videoconferencias a través de Zoom o Google Meet, recursos de construcción colaborativa como el paquete de Google Drive o Padlet, etc.

- Espacios de comunicación efectiva y acompañamiento: aquí aparece el interés por parte de estudiantes en mantener y reforzar canales de comunicación virtual con sus docentes y entre compañeros y compañeras, a través de por ejemplo grupos de WhatsApp, correo electrónico y foros en aulas virtuales. En este punto se destaca además, la importancia de seguir reforzando y desarrollando la horizontalidad en la relación con docentes y su acompañamiento durante el proceso de enseñanza aprendizaje.

- Nada: 22 personas de las 194 encuestadas manifestaron que no debería mantenerse en el futuro ninguna herramienta ni aspectos de la educación virtual en la post pandemia.

\section{Discusión y conclusiones}

El recorrido a través de la expresión de estudiantes en ejercicio de una autorreflexión sobre su propia experiencia de aprendizaje sirve para bosquejar un mapa 
de fortalezas y debilidades cuyos bordes y relieves ya advertimos en el proceso educativo incluso antes de la pandemia.

La inmersión precipitada en los entornos virtuales de aprendizaje sacudió las bases de la normalidad acostumbrada del sistema educativo. Lo que salió a la luz, fue un esfuerzo inagotable por parte de los docentes, quienes se entregaron con creatividad y valentía a la ardua tarea de cumplir sus funciones en un ambiente para muchos desconocido. Se manifestó, además, el deseo de aprender, expresarse y comunicarse por parte de los y las estudiantes, junto a una manifestación de insuficiencias y desafíos, que ponen en evidencia la distancia entre la situación actual y la deseada.

A partir de los datos recopilados sobre la experiencia de las y los estudiantes en periodo de aislamiento, se evidencian los obstáculos a superar y cuestionamientos sobre cómo generar una educación comprometida con el pleno desarrollo de las personas y sociedades. Una educación con conciencia de las transformaciones en el entorno y la evolución tecnológica, pero a la vez con eje en las personas, sus libertades y potencialidades. Escuchar lo que tienen que decir las y los jóvenes protagonistas de todos los niveles del sistema educativo, y aprender de quienes aprenden, es un primer paso hacia la conquista de una educación que, sin olvidar el pasado, habite su tiempo y avance en la construcción de la sociedad que cada persona merece.

El tiempo de consumo pasivo, de ciudadanía pasiva, de estudiantes pasivos/as no pudo resistir a la consolidación de los ambientes digitales y la conexión global e instantánea de la comunicación digital interactiva. Sin embargo, no hay que confundir la posibilidad de autogestionar con el criterio para hacerlo. Las personas pueden autogestionar su experiencia comunicativa, pero eso no les infunde automáticamente la capacidad para el logro de sus objetivos ni tampoco se garantiza una participación y una comunicación genuina por la mera introducción de la tecnología. La autogestión es también un aprendizaje y en un entorno cambiante y desafiante se hace cada vez más necesario que las y los estudiantes aprendan a aprender para un mundo en constante transformación que exige soluciones cada vez más creativas para problemas cada vez más complejos.

Frustrarse, confundirse y aburrirse. No es posible separar la educación de la realidad dentro de la cual el proceso educativo está inserto, en un contexto de incertidumbre creciente y frente a una imagen de futuro que se presenta cada vez más oscura y difusa. En este sentido, no es sorprendente que los estudiantes experimenten emociones negativas y tengan problemas para encontrar seguridad y satisfacción durante el proceso de aprendizaje.

En este aspecto los datos son contundentes, las y los estudiantes se aburren, se confunden y terminan por frustrarse. Ya era difícil motivar a las y los estudiantes en periodo pre-pandémico ¿Como producir una mejora en las prácticas, en medio de un escenario abrumador en el que ni estudiantes, ni profesores, ni gestores educativos han logrado aún hacer pie y conducirse firmemente? 
El primer paso, como en toda situación de crisis, es conservar la calma y confirmar la solidez de las bases. El fomento de los valores y la dignidad humana, el placer en el conocimiento, la expresión de la creatividad y el trabajo, la concordia social y el respeto por la vida son aspectos inseparables del proceso educativo ya sea que este se realice en un aula o a través del celular y a kilómetros de distancia.

El aburrimiento, la confusión y la frustración, no son emociones surgidas espontáneamente como consecuencia únicamente de la pandemia. Como en todos los ámbitos de la sociedad, el periodo de aislamiento magnificó el impacto de problemas estructurales que el sistema educativo arrastraba desde hace tiempo, sin solución o con intentos tímidos de superación. Lo importante a tener en cuenta sobre este aspecto es que las herramientas digitales por sí mismas, no son ni la causa ni la solución a todos los problemas: ni aliados incuestionables, ni enemigos mortales. Las herramientas están ahí, tienen diferentes características, sirven a diferentes fines, pueden ser adaptadas o transformadas para que respondan mejor a otros objetivos, no son enigmas producto de mentes superiores, son implementaciones humanas que tienen que ser pensadas dentro de procesos más amplios que nunca pueden estar rendidos a la tecnología.

Del otro lado de las pantallas, después del trayecto de cables y por fuera de las micro composiciones electrónicas siguen estando las y los jóvenes de antes, sus cuerpos energéticos, sus emociones variables y sus mentes en formación, rebeldes y contestatarios a la vez que atentos a la orientación. Las herramientas digitales por sí mismas pueden entretener, pueden informar y hasta pueden enseñar. El valor diferencial, entonces, sólo puede estar en los vínculos humanos. Y es allí donde las y los educadores pueden desplegar su calidad como 'guías' o tutores de un proceso de aprendizaje, que encuentre valor en el conocimiento, calidez en las prácticas y motivación.

En busca de los lazos perdidos. Las respuestas demuestran que en momentos como el que nos toca vivir actualmente, se hace cada vez más necesario recuperar los lazos perdidos; o quizás ir en busca de los nuevos lazos posibles y emerger de la crisis más solidarios, con lazos más fuertes y aún más unidos. Las y los estudiantes están en busca de conexiones más completas, algo que se parezca a los vínculos interrumpidos por la pandemia sin ser exactamente lo mismo.

La alta valoración de las clases virtuales encuentra su explicación en la mayor cantidad de sentidos involucrados: la posibilidad de vernos y escucharnos (no sólo leernos), en la semejanza con las modalidades prepandémicas de aprendizaje ¿Qué tan común es la imagen de un profesor o profesora que le pregunta al alumnado en una clase presencial, si tienen alguna duda y se encuentra frente a un público estático y en silencio? Mientras que en la virtualidad las herramientas que mejor permiten comunicarse y resolver las dudas son las más valoradas, justamente porque habilitan una posibilidad que antes estaba tan disponible que no se tenía en cuenta.

Por otro lado, el vínculo con los pares es también crucial en este aspecto y ha quedado un tanto relegado, frente a la dificultad por parte del profesorado de gestionar el trabajo grupal a la distancia. Preocupados antes por la realización efectiva de su trabajo 
y por acomodarse a los nuevos entornos digitales, el fomento del trabajo en equipo, en donde también se visualizaba una posible incompatibilidad producto de la distancia, quedó relegado y en buena parte, en manos de los mismos estudiantes. El patio del colegio, los espacios comunes en la universidad, como lugares de intercambio y dispersión están contenidos ahora en grupos de Whatsapp, en donde las y los estudiantes intercalan según su propia dinámica interna comentarios y contenido relacionado con las tareas y consignas de trabajo, con la conversación casual, el entretenimiento y la dispersión propia de la interacción informal entre pares. Este era un uso de la herramienta previo a la pandemia, desarrollado por lo general orgánicamente por impulso de las y los estudiantes sin intervención del personal docente y que resultó intensificado por la pérdida de los lazos presenciales atenuando sus efectos.

El desarrollo armónico del aprendizaje no puede ignorar la socialización y el intercambio entre pares. La cooperación para el logro de objetivos comunes incrementa la implicación de las y los estudiantes y pone en juego habilidades blandas fundamentales sin las cuáles las personas encuentran dificultades para el logro de sus objetivos sociales. Una vez superado el estado inicial de ubicación y acomodamiento al nuevo entorno virtual, será necesario idear estrategias para recuperar el trabajo en equipo y la colaboración, sin los cuales el aprendizaje queda truncado y las y los estudiantes limitados por la individualidad.

La competencia por la atención. La economía de la atención es un concepto que algunos autores comenzaron a desarrollar en las últimas décadas del siglo pasado. Herbert Simon señalaba en 1969 que un exceso de información generaba necesariamente una pobreza de atención (Celis Bueno, 2017). El concepto ha tomado relevancia en el presente a raíz de la inconmensurable cantidad de información circulante y la facilidad de acceso a la misma. La educación como proceso de construcción de saberes que involucra la transmisión de conocimiento y de información, se ve fuertemente interpelada por esta problemática. Claramente, las y los docentes corren con desventaja en la carrera por captar la atención de sus estudiantes, atraídos por la multiplicidad de pantallas simultáneas con las que de una manera u otra interactúan antes, durante y después de clases. Esa lucha desigual por captar la atención de sus alumnos se evidencia en este estudio y también en el relevamiento realizado a las y los docentes. Se evidencian los ingentes esfuerzos realizados, particularmente por estos últimos, para lograrlo y los resultados no siempre satisfactorios que se alcanzan. Esto lleva a pensar que, si bien es imprescindible realizar todas las adecuaciones a la enseñanza y al aprendizaje en la virtualidad, hay también situaciones preexistentes a la pandemia, que son necesarias de considerar si se pretende una mirada no reduccionista de los procesos educativos durante esta etapa de excepcionalidad. Se trata de reflexionar sobre los dispositivos tecnológicos contextualizados no solo en sus posibilidades de utilización en procesos educativos, si no también inscriptos en las culturas juveniles, para indagar en las representaciones y usos particulares que de ellos hacen las y los jóvenes, generalmente muy alejados de las expectativas de las y los docentes. 
El salto obligado. En una video-entrevista publicada en la página del Centro de Cultura Contemporánea de Barcelona, realizada por Jorge Carrión a Alessandro Baricco acerca de la actual crisis de salud mundial y sus posibles efectos, el destacado intelectual italiano aseguraba: "está crisis nos lanzará hacia el futuro".

La capacidad de adaptación que nos caracteriza como especie se manifestó en un flujo de energías a escala global orientadas hacia la transformación de nuestras pautas de convivencia y una mutación de nuestros modos de vida sin precedentes para la sociedad actual. Las medidas de aislamiento y la educación mudada al régimen virtual son expresiones de esa capacidad de adaptación y de la flexibilidad de las instituciones. La implementación de esta modalidad ya era una realidad posible, pero la pandemia nos obligó a dar el salto.

Ahora que aterrizamos, a los tropezones y sin mucha gracia, pero de pie en esta nueva realidad, es momento de estudiar el entorno y tomar acciones. En un contexto de transformación obligada, la realidad se encuentra más porosa y accesible para la introducción de innovaciones. La situación actual es una desgracia, pero dentro de la crisis tal vez sea posible encontrar nuevas soluciones a problemas viejos.

Casi el $90 \%$ de los encuestados cree que una vez superada la crisis la educación no va a volver a ser la misma. Los primeros escenarios imaginados apuntan a una hibridación de educación virtual y presencial que pueda contrarrestar las desventajas de un modo con las ventajas del otro. La clave del mejor desempeño de cada modalidad y su mejor combinación estará en la explotación de las especificidades de cada interfaz para obtener de cada espacio y de cada plataforma aquello que mejor pueda ofrecer. Rescatar la profundidad de los vínculos en los encuentros presenciales, no confundir los tiempos de la virtualidad con los de la presencialidad, cultivar la exploración, la creatividad y la libertad de las personas y que sean las máquinas quienes se encarguen de la eficiencia, puesto que para ello fueron creadas. Si el mundo está en un cambio constante y las certezas parecen alejarse y perderse en el horizonte, la educación que venga deberá enseñar para un futuro abierto y aprenderse a sí misma bajo el signo de la transformación.

\section{Bibliografía}

Freire, P., \& Faúndez, A. (1986). Hacia una pedagogía de la pregunta. Conversaciones con Antonio Faundez. Buenos Aires: Ediciones La Aurora.

Caldeiro, G. (2015). Aprendizaje ubicuo. Oportunidades para el desarrollo de propuestas educativas en línea. Recuperado de file:///C:/Users/Dise\% C3\% B1o/Downloads/Aprendizajeubicuo. pdf.

Celis-Bueno, (2017). Economía de la atención y visión maquínica: hacia una semiótica asignificante de la imagen. Hipertextos, 5(7), 41-55. 
Meirieu, Philip (2016) Recuperar la pedagogía. De lugares comunes a conceptos claves. Paidós. Barcelona.

Kaplún, M. (2010). Una pedagogía de la comunicación (Vol. 10). Ediciones de la Torre.

Martín-Barbero, J. (2000). Retos culturales: de la comunicación a la educación. Nueva sociedad, 169, 33-43.

Huergo, J. A., \& Fernández, M. B. (2000). Cultura escolar, cultura mediática/intersecciones (Vol. 1). U. Pedagógica Nacional. 